\title{
Estudo de caso das condições de abastecimento de água e esgotamento sanitário dos moradores da estação ecológica de Fernandes Pinheiro (PR)
}

\author{
Case about water supply and wastewater services of residents from the \\ ecological station of Fernandes Pinheiro (PR)
}

\author{
Maria Cecília Rosinski Lima Gomes ${ }^{1 *(*)}$ \\ Jeanette Beber de Souza ${ }^{2}$ \\ Cristina Ide Fujinaga ${ }^{3}$
}

\section{Resumo}

As ações de saneamento ambiental devem prover sanidade aos locais onde são praticadas as atividades humanas, a fim de promover a saúde da população, interrompendo o ciclo de transmissão de doenças. A saúde pública participa como ferramenta para as ações coletivas de saúde. Após constatar problemas de saúde em um grupo de famílias, moradoras de uma zona rural do Paraná, na Estação Ecológica de Fernandes Pinheiro, o presente trabalho dedicou-se a identificar a ocorrência de doenças infecciosas parasitológicas e alguns aspectos de saneamento básico presentes na área estudada. Foram verificados os fatores físicos, abastecimento de água e esgotamento sanitário de 4 famílias dessa população. $\mathrm{O}$ estudo realizado foi descritivo-observacional e procurou verificar a precariedade do saneamento básico com a prevalência de diarreia nos sujeitos envolvidos. Para o desenvolvimento do presente estudo foram realizadas entrevistas, visitas de campo, análises de laboratório e revisão bibliográfica. Estes procedimentos possibilitaram verificar inter-relação entre o indicador de saúde diarreia e a contaminação da água dos poços e rio. Os resultados obtidos revelaram a ocorrência de $27 \%$ de prevalência de diarreia, sendo a maioria entre crianças, além da contaminação da água por excretas, devido à falta de fatores de proteção dos locais de captação e à ausência da prática de desinfecção da água. A conclusão desta pesquisa deve incentivar a realização, por parte dos atores envolvidos no problema, quer seja o

I MSc.; Engenheira Ambiental; Pesquisadora do Instituto de Desenvolvimento Sustentável Mamirauá,Tefé,AM; Endereço: Rua Getúlio Vargas, 198, CEP: 69.470-000,Tefé,Amazonas, Brasil; E-mail: a_mcecilia@yahoo.com. br (*) Autor para correspondência.

2 Dra.; Engenheira Civil; Professora do Departamento de Engenharia Ambiental da Universidade Estadual do Centro-Oeste, UNICENTRO; E-mail: jeanettebeber@yahoo.com.br

3 Dra.; Fonoaudióloga; Professora da Universidade Estadual do Centro-Oeste, UNICENTRO; E-mail: cifujinaga@gmail.com

Recebido para publicação em 25/10/2010 e aceito em 09/04/2011

\begin{tabular}{llllll}
\hline Ambiência Guarapuava (PR) v.7 n.I & p. 25 - $38 \quad$ Jan./Abr. 20II ISSN I808 - 025 I
\end{tabular}

DOI: $10.5777 /$ ambiencia.2011.01.02 
Órgão Municipal Competente e/ou a população, que sejam implementadas ações preventivas e de infraestrutura que resultem em melhorias na saúde pública.

Palavras-chave: saúde pública; saneamento rural; prevalência de diarreia; Fernandes Pinheiro; Paraná.

\section{Abstract}

The actions of environmental sanitation must provide sanity to the places where human activities are practiced in order to promote the health care for population, breaking the cycle of disease transmission. The public health care participates as a tool for collective actions of health care. After checking health problems in a family group who were residents in rural area in Paraná, in ecological station in Fernandes Pinheiro city, this current work was supposed to identify the relation between the occurrence of parasitological infectious diseases and some aspects of basic sanitation system present in the studied area. It was checked physical factors, water supplying and sanitation sewage for 4 families of this population. This study was descriptive-observational and was supposed to relate the precarious situation to the basic sanitation with the prevalence of diarrhea in involved individuals. For the development of this present study, interviews were performed, visits in field, lab analysis and bibliographic review. Those proceedings became possible to check the interrelation among the health indicator diarrhea and the water contamination from wells and river. The obtained results indicated the occurrence of $27 \%$ of prevalence of diarrhea, being the major part among children, besides contamination in water through excretion, due to the lack of protection factors in caption locations and the absence of practice in water disinfection. The completion of this research should motivate an accomplishment for the involved actors in this problem, whether it is in the public organ from the city or the population, which can be implemented preventive action and infra-structure to outcome improvements in public health care.

Key words: public health; rural sanitation; diarrhea prevalence; Fernandes Pinheiro; Paraná.

\section{Introdução}

Ao se refletir sobre a relação entre a saúde pública e ambiental, destaca-se que essa relação está diretamente imbricada na prevenção de fatores de risco para a saúde humana e das populações. Considera-se que muitos desses fatores não se restringem às situações e comportamentos individualmente, mas envolvem também dimensões sociais, políticas e institucionais. Assim, não se podem separar os efeitos dos fatores fisiológicos do ser humano, daqueles relativos ao meio ambiente. Pois um, potencializa o outro, além do que, muitos dos efeitos juntos contribuem para a imagem da classe social das famílias, 
diferenciando o acesso aos serviços sociais e a qualidade de vida.

Ao contrário do que acontece nos países desenvolvidos, nos quais a primeira causa de mortalidade no período perinatal é a malformação congênita, intercorrência praticamente impossível de ser evitada, no Brasil, a maioria dos óbitos perinatais é determinada pelas condições de atendimento à gestante, à parturiente e ao recém-nascido, situações passíveis de serem enfrentadas pelos profissionais de saúde e respectivos serviços. Certamente, as condições ambientais, com destaque ao tratamento de água e esgoto, são componentes importantes que os gestores públicos devem enfatizar nas políticas públicas em saúde para a prevenção da morbi-mortalidade infantil. Neste contexto, é importante destacar que mães desnutridas, de baixo poder aquisitivo e escolaridade, procedentes de lugares sem saneamento básico e com pouco acesso aos serviços de saúde pública e infraestrutura, como ocorre em muitas regiões do Brasil, constituem-se grupos de alto risco, que engrossam as estatísticas da alta prevalência das doenças infecciosas infantis, entre elas a diarreia. No futuro, essas mesmas condições socioeconômicas e ambientais de risco interferirão negativamente no processo de crescimento e desenvolvimento infantil.

O sintoma predominante das doenças relacionadas ao saneamento, e que têm veiculação hídrica, é a diarreia (HELLER, 1997). Podendo ser definida como a passagem de três ou mais movimentos intestinais líquidos em $24 \mathrm{~h}$, assume tal relevância que o termo enfermidades diarreicas abarca inúmeras moléstias com nítida interface com a infraestrutura sanitária das comunidades. Sendo que a diarreia infantil é um importante problema de saúde em todo o mundo.
Gross et al. (1989) estudaram a influência das condições do saneamento básico e habitação nos índices de prevalência de diarreia, em duas regiões habitacionais pobres de Belo Horizonte, no Estado de Minas Gerais, no ano de 1986. No estudo, avaliaram as residências de 140 famílias e os exames parasitológicos das 168 crianças de até seis anos. Os resultados obtidos demonstraram a ocorrência de quatro a doze episódios de diarreia anualmente por criança e que $78,8 \%$ delas estavam infectadas. Portanto, a comparação das condições habitacionais com os resultados parasitológicos, permitiu aos autores concluírem que o tipo de abastecimento de água influiu sobre a incidência de diarreia, enquanto que o tipo de instalações sanitárias apontou para a incidência e a duração. Ainda, nenhuma destas duas variáveis teve influência sobre a prevalência de parasitoses intestinais e, portanto, helmintíase e amebíase eram transmitidas principalmente via alimento, e sua ausência ou presença foi relacionada com o estado de higiene pessoal.

Em regiões rurais, onde não há acesso aos serviços públicos de saneamento, são utilizadas soluções alternativas para o abastecimento de água, bem como, a proteção das fontes de captação de água, que é muito importante, pois diminui sua susceptibilidade à contaminação por agentes causadores de doenças. Do mesmo modo, o destino adequado do esgoto sanitário é fundamental para evitar a poluição ambiental e interromper o ciclo de transmissão de doenças.

Dessa forma, buscou-se, nesse estudo de caso, descrever as condições de acesso e uso da água e esgotamento sanitário, bem como identificar a ocorrência de diarreia em um grupo de famílias, moradoras de uma 
zona rural do Paraná, na Estação Ecológica de Fernandes Pinheiro.

\section{Materiais e métodos}

Trata-se de um estudo de caso, realizado em uma área rural do Paraná, localizada na Estação Ecológica de Fernandes Pinheiro, no município de Fernandes Pinheiro, no estado do Paraná. Os atores da pesquisa foram os indivíduos de todas as famílias residentes nesta área de 532,13 hectares, no ano de 2007 e seus suportes de abastecimento de água e afastamento e tratamento de esgotos sanitários.

Para avaliar as condições do abastecimento de água e esgotamento sanitário das famílias, foram realizadas visitas ao local de estudo. Amostras de água de consumo foram coletadas em frascos esterilizados e transportados em recipiente resfriado até o laboratório. As amostras foram analisadas aproximadamente $6 \mathrm{~h}$ após a coleta e os ensaios tiveram duração de dois dias. A metodologia utilizada na análise baseia-se na Filtração em Membranas e contagem de unidades formadoras de colônia em meio de cultura seletivo (APHA, 1998), para a presença de coliformes totais e Escherichia coli.

Como instrumento para padronização das informações a serem coletadas, utilizouse o questionário baseado no trabalho de Amaral et al. (2003). As entrevistas foram realizadas em um único dia e as respostas foram fornecidas pelas donas-de-casa.

\section{Relato dos casos}

O município de Fernandes Pinheiro localiza-se no sudeste do Paraná $\left(25^{\circ} 25^{\prime} \mathrm{S}\right.$ e $50^{\circ} 32^{\prime} \mathrm{W}$ ), na microrregião de Prudentópolis, a $138 \mathrm{~km}$ à oeste de Curitiba. Seu clima é subtropical com geadas frequentes no inverno, temperatura média anual de $17,5^{\circ} \mathrm{C}$, precipitação pluviométrica de $2328 \mathrm{~mm}$ por ano, com chuvas bem distribuídas e umidade relativa do ar média de 79,58\% (FERNANDES PINHEIRO, 2006).

A população, no período da pesquisa, era de 6688 habitantes, sendo predominantemente jovem e distribuída de forma irregular pelo território, sendo que 69\% dos moradores residiam na região rural, valor este que deve ser reduzido para 55\% até 2015, segundo o Plano Diretor Municipal de Uso e Ocupação do Solo (FERNANDES PINHEIRO, 2006).

O índice de desenvolvimento humano (IDH) de Fernandes Pinheiro, medido a partir do Censo de 2000, resultou em 0,711, abaixo da média do Estado $(0,797)$ e da região. No entanto, apesar de baixo, este índice é melhor do que o obtido em 1991, antes de sua emancipação. Esta evolução é reflexo, especialmente, da queda da mortalidade infantil e melhora nos níveis de educação obtidos nos últimos anos (FERNANDES PINHEIRO, 2006)

A renda familiar no município, em média, era de 0,73 salários-mínimos para cada um dos seus componentes (valor calculado para 2005, no Plano Diretor Municipal), portanto tem valor inferior à média estadual e também à média da microrregião de Prudentópolis (Estado do Paraná), da qual faz parte (FERNANDES PINHEIRO, 2006).

Quanto aos dados de saneamento básico de Brasil (2007), os 2.032 moradores da região urbana do município eram atendidos pela coleta convencional de resíduos sólidos e recebiam água tratada da Companhia de Saneamento do Paraná (SANEPAR). 
No tocante à água distribuída através do abastecimento público, é proveniente de manancial subterrâneo, localizado na sede do município, apresentando boa qualidade, recebendo apenas desinfecção com cloro e fluoretação. Quase 50\% das residências utilizavam a fossa negra para a deposição de águas servidas e $21,5 \%$ tinham fossa séptica. Ainda com relação a estas residências, 7,8\% despejam seu esgoto em valas, $0,2 \%$ em rio e 23,4\% não possuíam instalações sanitárias.

Durante esta pesquisa foi observado que, na região rural, geralmente, os moradores possuem as soluções alternativas e individuais de captação de água a seguir: poços freáticos, captação de rios e/ou nascentes. $\mathrm{O}$ esgotamento sanitário é feito também com soluções individuais, por fossas negras ou fossas sépticas, ou ainda as águas servidas são despejadas in natura em corpos d'água e no solo.

A Estação Ecológica de Fernandes Pinheiro é uma Unidade de Conservação de Proteção Integral, criada pelo Decreto Estadual no 4.230 de 5 de junho de 2001 e, na época do estudo, a área não possuía Plano de Manejo. Portanto, algumas inconformidades foram encontradas, como a presença irregular de moradores. Esta população, que foi alvo do presente trabalho, apesar de residir em área rural, não praticava atividades agrícolas e a renda das famílias devia-se, principalmente, ao trabalho informal e a programas sociais do Governo Federal.

Após a constatação de casos crônicos de diarreia na população (infantil e adulta), no Departamento Municipal de Vigilância Sanitária, vinculado à Secretaria Municipal de Saúde, iniciaram-se, periodicamente, exames de qualidade da água consumida pela comunidade em questão. Mensalmente foram realizadas análises de coliformes totais, coliformes termotolerantes e Escherichia coli, em dois pontos amostrais a partir dos quais a população captava água. $\mathrm{O}$ primeiro ponto estava localizado no Arroio dos Coxinhos e o segundo, constituía-se de poço raso na mesma bacia hidrográfica.

Desde o início do monitoramento da qualidade microbiológica da água destas fontes, segundo dados não publicados, obtidos junto ao Departamento Municipal de Vigilância Sanitária, todos os valores encontrados foram muito acima dos padrões estabelecidos pela Portaria do Ministério da Saúde n 518/2004 (BRASIL, 2004).

\section{Discussão dos resultados}

Os dados obtidos no presente estudo mostraram que $40 \%$ das pessoas consideravam sua água para consumo de boa qualidade (Tabela 1). Estes dados foram comparados com os dados apresentados por

Tabela I. Opinião dos entrevistados da população na Estação Ecológica de Fernandes Pinheiro, sobre a qualidade da água para consumo humano

\begin{tabular}{l|cccc}
\hline \multicolumn{1}{c|}{ Opinião } & \multicolumn{4}{c}{ Residência } \\
\hline Otima & - & - & - & - \\
Boa & - & - & $\mathrm{X}$ & $\mathrm{X}$ \\
Boa e melhor que a da cidade & - & - & - & - \\
Boa a leva para tomar na cidade & - & - & - & - \\
Boa e melhor da região & - & - & - & - \\
Ruim & $\mathrm{X}$ & $\mathrm{X}$ & - & - \\
\hline
\end{tabular}


Amaral et al. (2003), na região nordeste do Estado de São Paulo, em que 36,8\% das pessoas consideravam a água de boa ou ótima qualidade.

Este fato deve explicar o observado na tabela 2, que demonstra a ausência da prática de desinfecção em $75 \%$ das residências. Ainda, mesmo naquelas em que a fervura (residência 2) ou cloração (residência 1) da água eram realizadas, constatou-se que estas práticas não eram frequentes. Este comportamento deve relacionar-se ao fato de que um "bom" aspecto da água remete à impressão de boa qualidade, ou seja, não existe a necessidade de desinfecção.

Sendo que $50 \%$ dos entrevistados consideravam ruim a água que consumiam e tinham alguma ideia sobre a possibilidade de adquirirem alguma doença através da água que consumiam.

As condições do abastecimento alternativo de água da população são expostas na tabela 3, que demonstram que a solução encontrada para o abastecimento de água enquadra-se como uma solução alternativa (PORTARIA DO MINISTÉRIO DA SAÚDE no 518/2004, BRASIL, 2004).

A utilização de poços rasos em três residências, confirma a opção por este tipo de captação nas áreas rurais. Isto ocorre, provavelmente, pela facilidade de obtenção destas águas e possibilidade de instalação próxima à residência. Este último fator pode ser determinante também da depreciação da qualidade da água, uma vez que a localização das instalações residenciais de disposição de excretas e de captação de água, quando não respeitadas as distâncias de segurança recomendadas representam um fator de risco.

A tabela 4 apresenta os resultados da avaliação dos fatores de proteção à contaminação da água, nos locais que se utilizavam e de água de poço. $\mathrm{O}$ ponto amostral cinco corresponde a um poço profundo e protegido, origem da água utilizada no escritório do Instituto Paranaense

Tabela 2. Tipo de tratamento de água realizado pelos entrevistados na Estação Ecológica de Fernandes Pinheiro

\begin{tabular}{lrrrr}
\hline \multirow{2}{*}{ Residência } & \multicolumn{4}{c}{ Tipo de tratamento da água } \\
\cline { 2 - 5 } & Filtração & Fervura & Cloração & Nenhum \\
\hline 1 & - & - & $X$ & - \\
2 & - & - & - & - \\
3 & - & - & - & $X$ \\
4 & - & - & $X$ \\
\hline
\end{tabular}

Tabela 3. Avaliação do tipo de abastecimento de água alternativo que era utilizado pelos entrevistados na Estação Ecológica de Fernandes Pinheiro

\begin{tabular}{cccccccc}
\hline Residência & \multicolumn{3}{c}{$\begin{array}{c}\text { Tipo de captação d'água } \\
\text { para consumo }\end{array}$} & \multicolumn{3}{c}{$\begin{array}{c}\text { Localização da fonte de captação d'água em } \\
\text { relação ao local de despejo de esgoto sanitário }\end{array}$} \\
\hline & Nascente & Poço & Rio & À montante & A jusante & Mesmo nível \\
\cline { 2 - 8 } 1 & - & X & - & - & - & X \\
2 & - & & $X$ & - & $X$ & - \\
3 & - & X & - & - & - & X \\
4 & - & X & - & - & - & X \\
\hline
\end{tabular}

Notas: $\quad$ I- À montante: o local de captação de água é localizado em cota acima do local de despejo de esgoto; 2- À jusante: o local de captação de água é localizado em cota abaixo do local de despejo de esgoto. 
Tabela 4. Avaliação da condição do poço de captação de água pelos entrevistados na Estação Ecológica de Fernandes Pinheiro

\begin{tabular}{|c|c|c|c|c|c|c|c|c|}
\hline \multirow[b]{2}{*}{ Residência } & \multicolumn{3}{|c|}{$\begin{array}{c}\text { Profundidade do poço } \\
\text { de captação }\end{array}$} & \multicolumn{5}{|c|}{ Tipos de proteção do poço de captação } \\
\hline & $\begin{array}{l}\text { Até } \\
20 \mathrm{~m}\end{array}$ & $\begin{array}{l}\text { Maior } \\
\text { que } 20 \mathrm{~m}\end{array}$ & $\mathrm{~N} / \mathrm{C}^{1}$ & $\begin{array}{l}\text { Calçada } \\
\text { ao redor } \\
\text { na fonte }\end{array}$ & Tampa & $\begin{array}{c}\text { Parede } \\
\text { externa } \\
\text { acima do } \\
\text { solo }\end{array}$ & $\begin{array}{l}\text { Revestimento } \\
\text { interno }\end{array}$ & Nenhuma \\
\hline$\overline{1}$ & $\mathrm{X}$ & - & - & - & $\mathrm{X}$ & - & - & - \\
\hline 3 & $X$ & - & - & $X$ & X & $X$ & $X$ & - \\
\hline 4 & - & - & $X$ & $\mathrm{X}$ & $\mathrm{X}$ & $\mathrm{X}$ & $\mathrm{X}$ & - \\
\hline 5 & - & - & $X$ & $X$ & $X$ & $X$ & $X$ & - \\
\hline
\end{tabular}

Nota: $I-N / C=$ não conhecido.

de Pesquisa Agropecuária (IAPAR) de Fernandes Pinheiro, localizado próximo ao local de estudo, inserido nas análises com objetivo de ser um parâmetro de comparação.

Os fatores de proteção incluem, além dos listados na tabela 4 , os aspectos distanciamento horizontal e vertical em relação ao local de despejo sanitário (Figuras 1 e 2). $\mathrm{Na}$ prática, este distanciamento regula o uso do solo próximo ao poço. Segundo Chaves (2007), esta medida serviria para proteger e garantir a qualidade da água do aquífero por longo prazo, reduzindo o custo e o tempo associado à recuperação da qualidade da água.

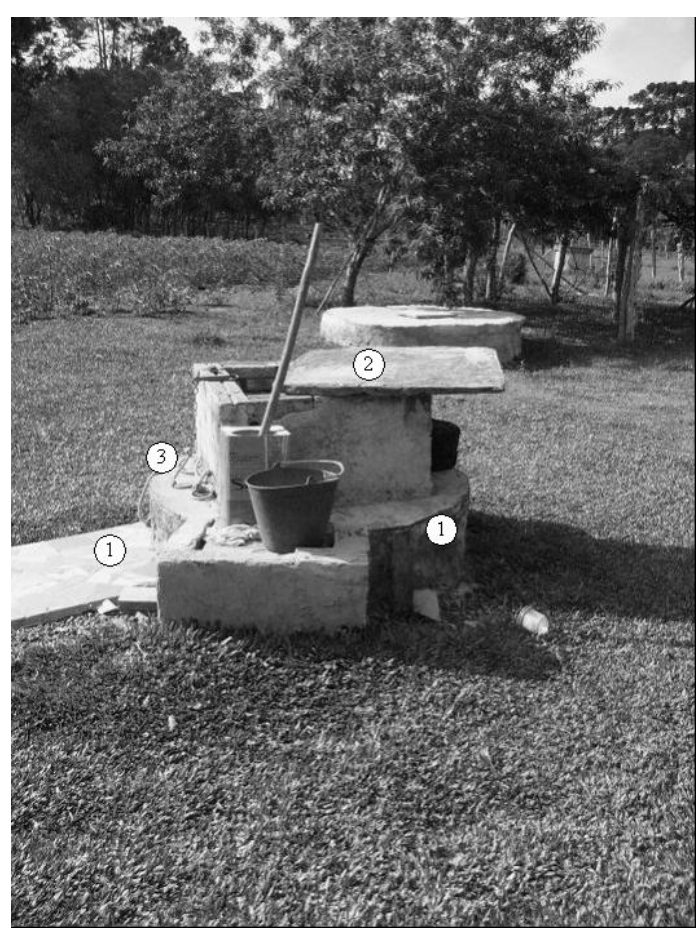

Figura I. Poço raso de captação de água na Estação Ecológica de Fernandes Pinheiro, com alguns fatores de proteção, correspondente ao ponto amostral 3

Notas: I- Calçada ao redor do poço; 2-Tampa; 3- Parede externa acima do solo. 


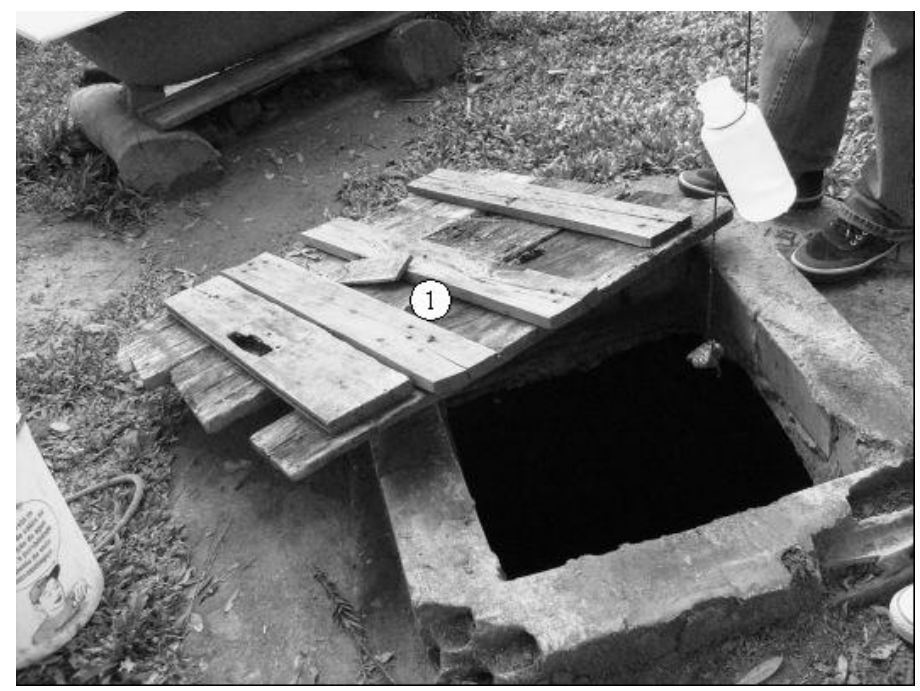

Figura 2. Poço raso de captação de água, na Estação Ecológica de Fernandes Pinheiro, correspondente ao ponto amostral I

Nota: I-Tampa.

Deste modo, considerando o ilustrado nas tabelas 3 e 4, nenhum dos três poços possuía proteção completa. Amaral et al. (2003), também constataram em sua pesquisa realizada no Estado de São Paulo, que nenhuma fonte de captação apresentou 100\% dos fatores de proteção da fonte de água. Carvalho (1984), analisando trinta poços rasos na região de Ibirité-MG encontrou $53 \%$ deles (16 poços) sem os aspectos adequados de construção e higiene.
Kravitz et al. (1999) defendem que a proteção das fontes de abastecimento pode preservar a qualidade da água no meio rural onde a desinfecção não é realizada, sendo que, cada fator de proteção tem sua importância, e a ausência de um deles já é motivo de preocupação. $\mathrm{Na}$ realidade, a pesquisa realizada por Kravitz et al. (1999), em Lesotho na África, mostrou que a proteção adequada da fonte de captação promoveu a prevenção efetiva da entrada de $E$. coli, melhorando a

Tabela 5. Avaliação do tipo de esgotamento sanitário utilizado pelos entrevistados na Estação Ecológica de Fernandes Pinheiro

\begin{tabular}{|c|c|c|c|c|c|c|}
\hline \multirow{4}{*}{ Residência } & \multicolumn{6}{|c|}{ Tipo de esgotamento sanitário } \\
\hline & \multirow{2}{*}{\multicolumn{2}{|c|}{$\begin{array}{c}\text { Fossa séptica } \\
\text { Distância da captação } \\
\text { de água }\end{array}$}} & \multirow{2}{*}{\multicolumn{2}{|c|}{$\begin{array}{c}\text { Fossa negra } \\
\begin{array}{c}\text { Distância da captação de } \\
\text { água }\end{array} \\
\end{array}$}} & \multirow{3}{*}{$\begin{array}{c}\text { Disposição } \\
\text { no solo }\end{array}$} & \multirow{3}{*}{$\begin{array}{l}\text { Lançamento } \\
\text { em corpo } \\
\text { d'água }\end{array}$} \\
\hline & & & & & & \\
\hline & $\begin{array}{l}\text { Menor que } \\
30 \mathrm{~m}\end{array}$ & $\begin{array}{l}\text { Pelo } \\
\text { menos } \\
30 \mathrm{~m}\end{array}$ & $\begin{array}{l}\text { Menor que } \\
30 \mathrm{~m}\end{array}$ & $\begin{array}{l}\text { Pelo menos } \\
\quad 30 \mathrm{~m}\end{array}$ & & \\
\hline 1 & - & - & $\mathrm{X}$ & - & - & - \\
\hline 2 & - & - & $\overline{\mathrm{Y}}$ & - & X & - \\
\hline 3 & - & - & $\mathrm{X}$ & - & - & - \\
\hline 4 & - & $\mathrm{X}$ & - & - & - & - \\
\hline
\end{tabular}


qualidade higiênica da água mais efetivamente que quando a prevenção ocorreu no próprio local de chegada ou uso da água.

Quanto ao esgotamento sanitário nas áreas rurais do município, conforme mencionado anteriormente, este ocorre por fossas (secas e sépticas), disposição direta no solo e/ou lançamento em corpo d'água. $\mathrm{Na}$ área de estudo, as opções para afastamento e tratamento de esgoto são mostradas na tabela 5.

Foi constatado que em um dos locais (Figura 3), além de aspectos construtivos inadequados, o local de despejo de excretas estava a menos de $3 \mathrm{~m}$ de uma pequena plantação de hortaliças, utilizadas na alimentação familiar.

A Portaria no 518/04 emitida por Brasil (2004) estabelece, em seu Artigo 11, o padrão microbiológico de potabilidade da água para consumo humano. A seguir são apresentados os Valores Máximos Permissíveis (VMP):

- Escherichia coli ou coliformes termotolerantes: ausência em 100 mL;
- Coliformes totais: apenas uma amostra poderá apresentar mensalmente resultado positivo em $100 \mathrm{~mL}$ em sistemas que analisam menos de 40 amostras por mês.

Em complementação à exigência de qualidade microbiológica, o VMP (Valor Máximo Permissível) de turbidez para a água subterrânea é de 1,0 UNT (unidades nefelométricas de turbidez) em 95\% das amostras. Os 5\% que estivem acima do VMP não devem exceder 5,0 UNT. Os resultados das análises da água de consumo disponível para a população em questão são apresentados na tabela 6 .

Os resultados mais relevantes do presente estudo são os que se referem à qualidade microbiológica da água. Diante dos dados obtidos, pode-se observar que, nas residências 1, 2, 3 e 4, a quantidade de coliformes totais e $E$. coli é muito superior ao VMP para água potável. No ponto amostral número 1 , onde foram encontradas as piores condições do poço, foi encontrada também maior concentração de $E$. coli, em relação às amostras de água dos demais poços.

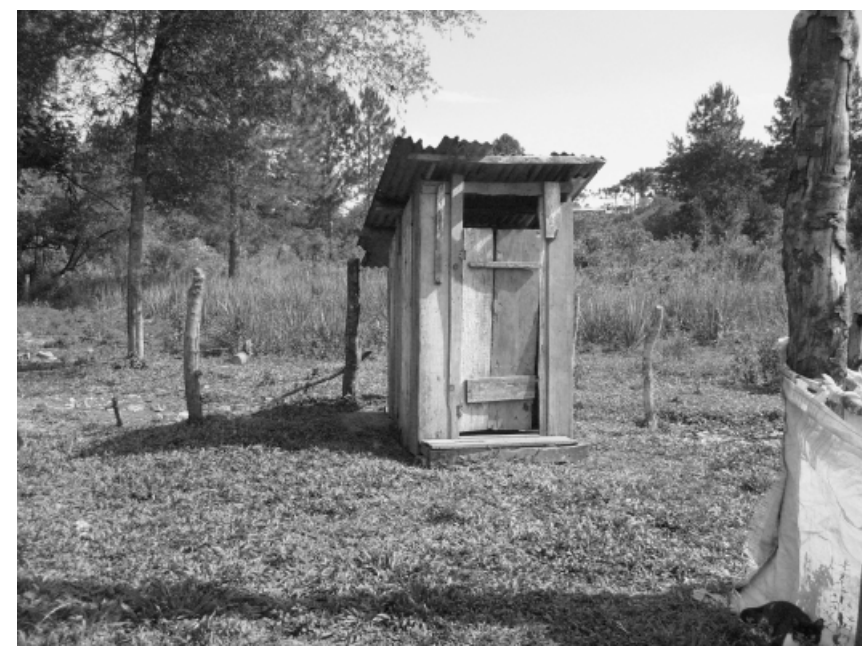

Figura 3. Fossa negra, local de disposição de excretas de uma residência na Estação Ecológica de Fernandes Pinheiro 
Com relação às análises de qualidade da água anteriores, realizadas pelos técnicos da Vigilância Sanitária, também revelaram altas concentrações de microrganismos indicadores de contaminação microbiológica (Tabela 7).

Os resultados apresentados nas Tabelas 6 e 7 referem-se à análise da água bruta. Estes valores ultrapassam também os Padrões dos Corpos d'Água de Classe Especial, estabelecido pela Resolução CONAMA n ${ }^{\circ}$ 357/2005 (BRASIL, 2005), que possuem os seguintes limites máximos: turbidez 40 UNT, coliformes termotolerantes de 200 $\mathrm{NMP} / 100 \mathrm{~mL}$ e os valores de $\mathrm{pH}$ devem estar entre 6 e 9.

Sobre a desinfecção da água, o Artigo 22 da Portaria MS n 518/04 (Brasil, 2004) determina que toda água distribuída coletivamente deve ser clorada, ou desinfetada por outro método comprovadamente eficiente. É importante destacar também que, de acordo com o Artigo 20 da mesma Portaria, sempre que forem identificadas situações de risco à saúde, o responsável pela operação do sistema ou solução alternativa de abastecimento de água e as autoridades de saúde pública devem estabelecer entendimentos para a elaboração de um plano de ação para que sejam tomadas providências para a correção da(s) anormalidade(s), como por exemplo, a comunicação à população.

$O$ resultado negativo para coliformes totais (CT) e E. coli, encontrado para o ponto cinco (Tabela 6), corrobora com a premissa de que a disposição adequada de esgoto sanitário, esta associada à construção e operação adequadas dos poços de captação

Tabela 6. Análise da qualidade da água de consumo dos entrevistados na Estação Ecológica de Fernandes Pinheiro

\begin{tabular}{lllll}
\hline Ponto amostral & $\begin{array}{l}\text { Coliformes totais } \\
\text { (CT) }\end{array}$ & $\begin{array}{l}\text { Escherichia coli } \\
\text { UFC/100 } \mathrm{mL}^{1}\end{array}$ & $\begin{array}{l}\text { Turbidez } \\
\mathrm{UNT}^{2}\end{array}$ & $\mathrm{pH}$ \\
\hline 1 & $\mathrm{UFC} / 100 \mathrm{~mL}^{1}$ & 2.500 & 22,75 & 6,21 \\
2 & 16.000 & 300 & 25,30 & 6,89 \\
3 & 16.500 & 350 & 3,07 & 5,46 \\
4 & 16.600 & 40 & 7,23 & 5,50 \\
5 & 70 & 0 & 0,44 & 7,96 \\
\hline
\end{tabular}

Notas: I- UFC/I00 mL: unidades formadoras de colônia em $100 \mathrm{~mL}$ de amostra; 2- UNT: unidades nefelométricas de turbidez.

Tabela 7. Análises da qualidade da água de consumo dos entrevistados da Estação Ecológica de Fernandes Pinheiro, realizadas em 2006 e 2007

\begin{tabular}{|c|c|c|c|c|c|}
\hline \multirow[b]{2}{*}{$\begin{array}{c}\text { Ponto } \\
\text { amostral }^{1}\end{array}$} & \multirow[b]{2}{*}{ Procedência } & \multicolumn{2}{|c|}{20 de junho de 2006} & \multicolumn{2}{|c|}{17 de outubro de 2007} \\
\hline & & $\begin{array}{c}\text { Coliformes } \\
\text { totais }(\mathrm{CT}) \\
\mathrm{NMP} / 100 \mathrm{~mL}^{2}\end{array}$ & $\begin{array}{c}\text { Coliformes } \\
\text { termotolerantes } \\
\text { (CF) } \\
\mathrm{NMP} / 100 \mathrm{~mL}^{2}\end{array}$ & $\begin{array}{c}\text { Coliformes } \\
\text { totais }(\mathrm{CT}) \\
\text { NMP/100mL }\end{array}$ & $\begin{array}{l}\text { Escherichia } \\
\text { coli } \\
\text { UFC/100 } \mathrm{mL}^{3}\end{array}$ \\
\hline & & $\begin{array}{l}>2419,6 \\
>2419,6\end{array}$ & $\begin{array}{l}1119,9 \\
60,2\end{array}$ & $\begin{array}{l}>2419,6 \\
>2419,6\end{array}$ & $\begin{array}{l}2419,6 \\
133,4\end{array}$ \\
\hline
\end{tabular}

Fonte: dados não publicados, obtidos junto ao Departamento municipal de Vigilância Sanitária

Notas: I- os pontos amostrais I e 2 referem-se aos mesmos pontos I e 2 das demais tabelas; 2- NMPII00 mL: número mais provável em 100 mL de amostra;3- UFC/100 mL:unidades formadoras de colônia em 100 mL de amostra. 
d'água, é indispensável para a manutenção da qualidade da água.

Os moradores da Estação Ecológica de Fernandes Pinheiro são instruídos por agentes comunitários e da vigilância sanitária a procederem a desinfecção da água de consumo com hipoclorito de sódio. Este desinfetante possui concentração de cloro livre disponível de $2,5 \%$ e é fornecido pelo Ministério da Saúde, sendo distribuído pela vigilância sanitária e também disponibilizado nas unidades de saúde de cada localidade do município.

Para comprovar a utilização do hipoclorito de sódio e assegurar a correta desinfecção da água, após cinco distribuições, os técnicos da vigilância sanitária realizavam in loco um teste para verificação de cloro residual, com o corante ortotolidina. $\mathrm{O}$ resultado da maioria dos testes com ortotolidina realizados, segundo os técnicos da vigilância sanitária, foi negativo, ou seja, os moradores não realizavam a desinfecção. Esta situação pode ser comprovada pelo resultado do questionário aplicado, onde, em nenhuma das residências estudadas a prática de algum tipo de desinfecção foi considerada regular.

Sobre o indicador de saúde prevalência de diarreia, a constatação foi feita de acordo com a informação dada pelo responsável de cada residência visitada (Figura 4).

Faz-se necessário considerar, na determinação da prevalência de diarreia, os erros a que os resultados podem estar submetidos, devido, principalmente, a pouca atenção que as pessoas dedicam a este tipo de ocorrência, sobretudo quando a mesma torna-se frequente.

Apesar disso, pode-se comparar estes resultados com os dados encontrados em um assentamento subnormal de Juiz de Fora (MG) do trabalho de Teixeira e Heller (2005), onde 46,1\% das crianças que tinham aproximadamente 3 anos de idade, possuíam os sintomas de diarréia há menos de 15 dias. Onde os autores constataram que os indicadores estrutura familiar,

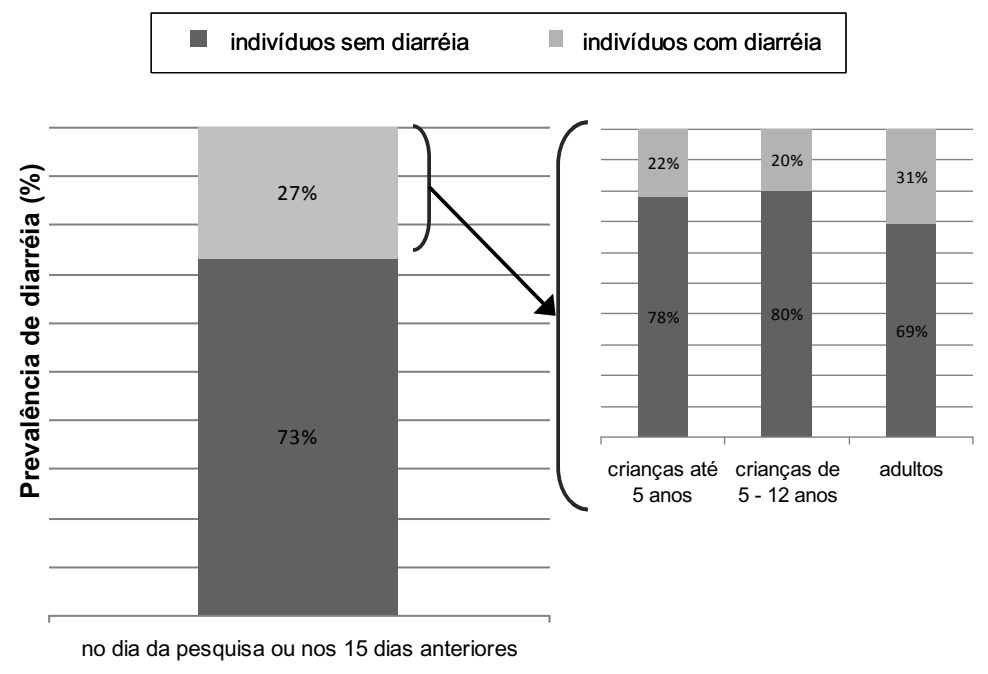

Figura 4. Prevalência de diarreia dos entrevistados na Estação Ecológica de Fernandes Pinheiro (novembro de 2007) 
estado nutricional, nível socioeconômico, abastecimento de água e esgotamento sanitário demonstraram associação estatística com a diarreia. Uma vez que a prevalência de $46,1 \%$, encontrada em Juiz de Fora é superior à registrada na presente pesquisa, que foi de $27 \%$. Este fato pode estar relacionado com as condições insalubres de moradia no assentamento subnormal, no qual as casas constituem-se de barracos construídos em madeira, tijolos e lona.

Teixeira e Heller (2005) puderam também estabelecer um risco significativo de ocorrência de diarréia 2,5 vezes maior quando o consumo de água era de mina ou nascente, em comparação com o consumo de água tratada fornecida pelo sistema público. Este resultado corrobora o encontrado por Esrey et al. (1990) referenciado por Teixeira e Heller (2005) em que, por meio da análise de 144 estudos de diversos locais do mundo, pode-se concluir que melhorias no abastecimento de água (na qualidade e quantidade) levaram a uma redução de $17 \%$ na morbidade por diarreia.

Já no trabalho de Kravitz et al. (1999) foram registrados casos de prevalência de diarreia em $18 \%$ das crianças de até 5 anos em Lesotho, na África. Este índice foi atribuído às condições inapropriadas de saneamento básico em $62 \%$ dos locais de captação de água das residências. Pois, além do contato das pessoas com coleções de águas contaminadas, encontrou-se ausência de latrinas em 95\% das residências e hábitos não-higiênicos da população.

Quando se compara os resultados das análises microbiológicas da água e dos suportes de saneamento básico da população investigada nesta pesquisa, pode-se conceber uma associação entre eles. Quanto aos pontos amostrais 2, 3 e 4, que possuíam os menores valores de contaminação por $E$. coli, respectivamente 300,350 e $40 \mathrm{UFC} / 100 \mathrm{~mL}$, indicaram as condições menos precárias no local de captação de água.

Por fim, a constatação da prevalência de diarreia nos indivíduos até 12 anos resultou em $100 \%$ na residência correspondente à pior qualidade da água (ponto amostral 1). Do mesmo modo, nas residências correspondentes aos pontos amostrais $2 \mathrm{e}$ 4, de menor contaminação por $E$. coli, onde havia moradores menores de doze anos de idade, nenhum apresentou diarreia no dia da visita e nos quinze dias anteriores.

\section{Conclusões e recomendações}

A precariedade do saneamento rural no Brasil leva a população a buscar soluções de baixo custo financeiro, mas que acabam tendo consequências indesejáveis. As condições do acesso à água e esgotamento sanitário, presentes na Estação Ecológica de Fernandes Pinheiro, contribuíram para problemas de saúde pública constatados na região.

Portanto, as condições inadequadas dos locais de captação de água, ausência de fatores de proteção do manancial e a disposição dos excretas em local inadequado vem promovendo a redução da qualidade da água utilizada para consumo humano. Juntamente com estes aspectos, os hábitos higiênicos precários e a ausência da prática de desinfecção da água são responsáveis pelo alto índice de prevalência de diarreia entre os habitantes da localidade.

Finalmente, recomenda-se que sejam estabelecidas rotinas para o monitoramento da qualidade da água em períodos de estiagem e de chuva, para que seja analisada a influência da lixiviação e escoamento da 
chuva na qualidade da água dos poços rasos. Sugere-se ainda que seja implantado um programa de educação sanitária e ambiental para acompanhamento das condições de saúde pública da população.

\section{Agradecimentos}

As autoras agradecem à Secretaria de Saúde e Secretaria de Agricultura, Pecuária e Meio Ambiente do município de Fernandes Pinheiro (PR).

\section{Referências}

AMARAL, L. A., NADER FILHO, A., ROSSI JÚNIOR, O. D., FERREIRA, L. A. e BARROS, L. S. S. Água de consumo humano como fator de risco à saúde em propriedades rurais. Revista de Saúde Pública, São Paulo, v. 37, n. 4, 2003.

APHA - AMERICAN PUBLIC HEALTH ASSOCIATION. Standard Methods for the Examination of Water and Wastewater, 19 ed., Washington, 1998.

BRASIL, Ministério da Saúde. Indicadores municipais de saúde. Disponível em: <http:// portal.saude.gov.br/portal/aplicações/tabfusion/tabfusion.cfm>. Acesso em: 5 nov. 2007.

BRASIL, Ministério da Saúde. Portaria n ${ }^{\circ}$ 518. Controle e qualidade da água para consumo humano e seu Padrão de Potabilidade. Ministério da Saúde. Fundação Nacional de Saúde. 2004.

BRASIL, Ministério do Meio Ambiente. Resolução n ${ }^{\circ}$ 357. Classificação dos corpos d'água e padrões de lançamentos de efluentes. Ministério do Meio Ambiente. Conselho Nacional do Meio Ambiente, 2005.

CAIRNCROSS, S.; BLUMENTHAL, U.; KOLSKY, P.; MORAES, L.; TAYEH, A. The public and domestic domains in the transmission of disease. Tropical Medicine and International Health, v.1, n.1, p. 27-34. 1996

CARVALHO, A. C. F. B. Contaminação de poços rasos por bactérias do grupo coliformes e estreptococos fecais em Minas Gerais. Semina: Ciências Agrárias, Londrina, v. 5, n.16, p. 57-60, (edição especial). 1984.

CHAVES, A. Análise dos recursos hídricos subterrâneos no município de São Luis Gonzaga, RS. 2007. 119f. Trabalho de conclusão de curso (Graduação em Geografia). Universidade Federal de Santa Maria. Santa Maria, RS, 2007.

FERNANDES PINHEIRO. Plano Diretor de Uso e Ocupação do Solo Municipal de Fernandes Pinheiro. Fernandes Pinheiro, 2006.

GROSS, R.; SCHELL, B.; MOLINA, M.C.B.; LEÃO, M.A. C.; STRACK, U.The impact of improvement of water supply and sanitation facilities on diarrhea and intestinal parasites: a Brazilian experience with children in two low-income urban communities. Revista de Saúde Pública, São Paulo, v. 23, n.3, p. 214-220, 1989. 
HELLER, L. Saneamento e Saúde. Brasília: Organização Pan-Americana de Saúde - OPAS/ OMS - Representação do Brasil, 1997. Disponível em: <http://www.opas.org.br/ambiente/ UploadArq/Saneam_Saude_Final.pdf.>

KRAVITZ J. D.; NYAPHISI, M.; MANDEL, R.; PETERSEN, E. Quantitative bacterial examination of domestic water supplies in Lesotho Highlands: water quality, sanitation and village health. Bulletin of the World Health Organization, v. 77, n. 10, p. 829-840. 1999.

TEIXEIRA, J. C.; HELLER, L. Fatores ambientais associados à diarréia infantil em áreas de assentamento subnormal em Juiz de Fora, Minas Gerais. Revista Brasileira de Saúde Materna e Infantil, Recife, v. 5 n. 4, p. 449-455, 2005. 